\title{
Correction to: Ontopolitics at Play: Inclusion Between a Panacea and a Hook
}

Correction to:

Chapter 4 in: J. Pospisil, Peace in Political Unsettlement, Rethinking Peace and Conflict Studies, https://doi.org/10.1007/978-3-030-04318-6_4

In the original version of the book (on page 120 of Chapter 4 ), the text read 'an association', rather than 'a community'. The correction has now been made.

The updated version of this chapter can be found at https://doi.org/10.1007/978-3-030-04318-6_4

(C) The Author(s) 2019

J. Pospisil, Peace in Political Unsettlement, Rethinking Peace and Conflict Studies, https://doi.org/10.1007/978-3-030-04318-6_8 